\title{
Coffee and tea consumption in the Scottish Heart Health Study follow up: conflicting relations with coronary risk factors, coronary disease, and all cause mortality
}

\author{
Mark Woodward, Hugh Tunstall-Pedoe
}

\begin{abstract}
Study objective-To relate habitual (cups per day) tea and coffee consumption to conventional coronary risk factors and subsequent risk of coronary heart disease and death.

Design-Cohort study.

Setting-Nationwide random population study.

Participants-Over 11000 men and women aged 40-59 who took part in the Scottish Heart Health Study lifestyle and risk factor survey in 1984-87. Participants were followed up to the end of 1993, an average of 7.7 years, for all cause mortality, coronary death, or any major coronary event (death, non-fatal infarction or coronary artery surgery). Cox's proportional hazards regression model was used to estimate the hazard in consumers of tea and coffee relative to the zero consumption group, both before and after correction for other factors.

Main results-Coffee and tea consumption showed a strong inverse relation. For many conventional risk factors, coffee showed a weak, but beneficial, gradient with increasing consumption, whereas increasing tea consumption showed the reverse. Increasing coffee consumption was associated with beneficial effects for mortality and coronary morbidity, whereas tea showed the opposite. Adjusting for age and social class had some effect in reducing associations. Multiple adjustment for other risk factors removed the associations for tea and most of those for coffee although there was a residual
\end{abstract}

29 January 1999 benefit of coffee consumption in avoiding heart disease among men.

Conclusions-The epidemiological differences shown in this study occurred despite the pharmacological similarities between tea and coffee. Either they differ more than is realised, or they identify contrasting associated lifestyle and health risks, for which this multiple adjustment was inadequate.

(F Epidemiol Community Health 1999;53:481-487)

Coffee drinking has been said to provoke arrhythmias and dilate coronary arteries, although the available evidence is sometimes contradictory. ${ }^{1}$ Meta analyses have either found no overall effect of coffee on coronary heart disease $(\mathrm{CHD})^{23}$ or an effect only in case-control studies. ${ }^{4}$ Tea drinking has been thought to be of potential benefit for avoiding CHD, mainly because of antioxidant constituents. ${ }^{67}$ The general picture from past research is similar for other diseases, including cancer: large amounts of coffee might constitute a risk ${ }^{8}$ but tea drinking might be protective. $^{810}$

Despite the general impression that high coffee consumption is "bad", we have previously found the prevalence of CHD to be highest among those who abstain from coffee drinking and lowest among those who drink five or more cups per day in Scotland. ${ }^{11}$ The purpose of the current article is to see whether the previous findings are reproduced when incidence data are used. The study group has been monitored longitudinally for all cause mortality, as well as $\mathrm{CHD}$, and both are reported here. Unlike many previous cohort studies, this study uses a large random population sample of both men and women. Studies on specific groups ${ }^{12}{ }^{13}$ may lack general applicability. Relatively few studies have been carried out in the United Kingdom, especially with regard to tea.

\section{Methods}

The Scottish Heart Health Study (SHHS) randomly sampled men and women aged 40-59 years from 25 districts in Scotland between 1984 and 1987. The response rate was $74 \%$. Each participant completed a postal questionnaire and attended a clinic where it was checked, a 12 lead electrocardiogram (ECG) was applied and a blood sample was taken. Coffee and tea consumption were reported as the number of cups usually drunk

Variables are listed in rank order of absolute correlations with tea for women (the largest group). ${ }^{\star} \mathrm{p}<0.01,{ }^{\star \star} \mathrm{p}<0.001,{ }^{\star \star \star} \mathrm{p}<0.0001$ 
Table 2 Medians of quantitative confounding variables by coffee group and tea group: men

\begin{tabular}{|c|c|c|c|c|c|c|c|c|c|c|c|}
\hline Cups/day & $\begin{array}{l}\text { Alcohol } \\
\text { (units/wk) }\end{array}$ & Age (y) & $\begin{array}{l}\text { Bortner } \\
\text { score }\end{array}$ & $\begin{array}{l}\text { Vitamin } C \\
\text { (mg/day) }\end{array}$ & $\begin{array}{l}\text { Triglycerides } \\
\text { (mmoll/) }\end{array}$ & $\begin{array}{l}\text { Systolic BP } \\
(m m \mathrm{Hg})\end{array}$ & $\begin{array}{l}\text { Fibrinogen } \\
(\mathrm{g} / \mathrm{l})\end{array}$ & $\begin{array}{l}\text { Total } \\
\text { cholesterol } \\
(\text { mmol/l) }\end{array}$ & $\begin{array}{l}\text { Cotinine } \\
(\mathrm{ng} / \mathrm{ml})\end{array}$ & $\begin{array}{l}\text { HDL-chol } \\
\text { (mmol/l) }\end{array}$ & $\begin{array}{l}B M I \\
\left(\mathrm{~kg} / \mathrm{m}^{2}\right)\end{array}$ \\
\hline \multicolumn{12}{|l|}{ Coffee } \\
\hline 0 & 10 & 51 & 161 & 46.1 & 2.01 & 133 & 2.27 & 6.22 & 8 & 1.30 & 26.1 \\
\hline $1-2$ & 11 & 50 & 169 & 50.9 & 1.96 & 133 & 2.20 & 6.27 & 4 & 1.32 & 25.9 \\
\hline $3-4$ & 12 & 49 & 174 & 51.5 & 1.91 & 131 & 2.21 & 6.32 & 6 & 1.36 & 25.9 \\
\hline $\begin{array}{l}5+ \\
\text { Tea }\end{array}$ & 11 & 48 & 173 & 48.7 & 1.87 & 131 & 2.27 & 6.41 & 159 & 1.30 & 25.6 \\
\hline 0 & 13 & 47 & 175 & 47.9 & 1.91 & 133 & 2.25 & 6.38 & 19 & 1.32 & 26.0 \\
\hline $1-2$ & 13 & 49 & 172 & 52.3 & 2.00 & 132 & 2.20 & 6.39 & 6 & 1.36 & 26.0 \\
\hline $3-4$ & 11 & 50 & 169 & 49.4 & 1.94 & 132 & 2.21 & 6.26 & 6 & 1.31 & 26.0 \\
\hline $5+$ & 8 & 51 & 167 & 47.8 & 1.96 & 132 & 2.28 & 6.24 & 12 & 1.30 & 25.7 \\
\hline
\end{tabular}

Table 3 Medians of quantitative confounding variables by coffee group and tea group: women

\begin{tabular}{|c|c|c|c|c|c|c|c|c|c|c|c|}
\hline Cups/day & $\begin{array}{l}\text { Alcohol } \\
\text { (units/wk) }\end{array}$ & Age (y) & $\begin{array}{l}\text { Bortner } \\
\text { score }\end{array}$ & $\begin{array}{l}\text { Vitamin } C \\
\text { (mg/day) }\end{array}$ & $\begin{array}{l}\text { Triglycerides } \\
\text { (mmol/l) }\end{array}$ & $\begin{array}{l}\text { Systolic BP } \\
(m m \mathrm{Hg})\end{array}$ & $\begin{array}{l}\text { Fibrinogen } \\
(\mathrm{g} / \mathrm{l})\end{array}$ & $\begin{array}{l}\text { Total } \\
\text { cholesterol } \\
\text { (mmol/l) }\end{array}$ & $\begin{array}{l}\text { Cotinine } \\
\text { (ng/ml) }\end{array}$ & $\begin{array}{l}\text { HDL-chol } \\
(\mathrm{mmol} / \mathrm{l})\end{array}$ & $\begin{array}{l}B M I \\
\left(\mathrm{~kg} / \mathrm{m}^{2}\right)\end{array}$ \\
\hline \multicolumn{12}{|l|}{ Coffee } \\
\hline 0 & 0 & 50 & 166 & 43.2 & 1.47 & 131 & 2.36 & 6.46 & 3 & 1.60 & 25.3 \\
\hline $1-2$ & 2 & 51 & 168 & 50.8 & 1.44 & 130 & 2.28 & 6.51 & 2 & 1.65 & 24.8 \\
\hline $3-4$ & 3 & 49 & 171 & 51.5 & 1.31 & 127 & 2.26 & 6.51 & 2 & 1.69 & 24.9 \\
\hline $\begin{array}{l}5+ \\
\text { Tea }\end{array}$ & 4 & 48 & 173 & 48.4 & 1.31 & 125 & 2.29 & 6.45 & 17 & 1.63 & 24.7 \\
\hline 0 & 4 & 48 & 174 & 46.4 & 1.30 & 126 & 2.32 & 6.41 & 19 & 1.62 & 24.6 \\
\hline $1-2$ & 4 & 48 & 172 & 53.0 & 1.32 & 126 & 2.24 & 6.42 & 3 & 1.67 & 24.8 \\
\hline $3-4$ & 2 & 50 & 168 & 48.4 & 1.41 & 130 & 2.32 & 6.58 & 2 & 1.64 & 25.1 \\
\hline $5+$ & 1 & 51 & 167 & 45.8 & 1.44 & 130 & 2.34 & 6.48 & 3 & 1.64 & 24.9 \\
\hline
\end{tabular}

per day; specific types of coffee or tea were not identified. At baseline, subjects were classified positive for myocardial infarction if they reported a previous doctor diagnosis or if they exhibited Q/QS patterns on their ECG. ${ }^{14}$ Full details of the surveys have been published previously. ${ }^{15-17}$

Hospital discharges and operations and deaths were recorded for the 5754 men and 5875 women followed up until the end of 1993 (an average of 7.7 years of observation). This excludes 14 people lost to follow up because of emigration. The coronary events recorded during follow up could be fatal or non-fatal. Nonfatal events were taken to be a hospital diagnosis of myocardial infarction or coronary artery surgery. Details appear elsewhere. ${ }^{17}{ }^{18}$ In this article we consider three end points: coronary death, progressive CHD and all cases mortality. Progressive CHD is any coronary event except that recurrence of a non-fatal coronary event in a survivor does not qualify. That is, the event had to be a progression in severity. The three end points overlap in that a coronary death is a special case of each of the other two.

The effect of coffee and tea drinking might be confounded by other potential risk factors for CHD or all cause mortality. Based on previous literature, including our own results, ${ }^{17}$ we identified 16 potential confounding factors. These were age, occupational social class, housing tenure, activity at work, activity in leisure, cigarette smoking status, Bortner personality score, alcohol consumption, vitamin C intake, body mass index (weight divided by the square of height), (systolic) blood pressure, cotinine (a measure of current tobacco consumption), plasma fibrinogen, serum total and HDL-cholesterol, and serum triglycerides. The first nine of these were reported on the questionnaire. Housing tenure (owner occupier/renter) has been identified as the best measure of social status in this study, ${ }^{19}$ although, as the classification based on occupations is traditionally used, both are considered here. The two types of physical activity were each self reported as active/average/inactive. Cigarette smoking status also has three outcomes: current/ex/never. Alcohol is reported as the number of units drunk in the past week and vitamin $\mathrm{C}$ intake was estimated from the questionnaire using food consumption tables. ${ }^{20}$

Non-parametric procedures were used to compare coffee and tea consumption with the

Table 4 Percentages drinking various levels of coffee and tea within each occupational social class group ${ }^{\star}$ by sex

\begin{tabular}{|c|c|c|c|c|c|c|c|c|c|c|c|c|c|c|}
\hline \multirow[b]{2}{*}{ Cups/day } & \multicolumn{7}{|l|}{ Men } & \multicolumn{7}{|c|}{ Women } \\
\hline & $n$ & $I$ & $I I$ & IIIn & IIIm & $I V$ & $V$ & $n$ & $I$ & $I I$ & IIIn & IIIm & $I V$ & $V$ \\
\hline & & 382 & 1440 & 521 & 2194 & 763 & 265 & & 366 & 1386 & 749 & 1817 & 837 & 299 \\
\hline \multicolumn{15}{|l|}{ Coffee } \\
\hline 0 & 1646 & 13 & 20 & 23 & 35 & 34 & 52 & 1558 & 16 & 17 & 23 & 31 & 34 & 41 \\
\hline $1-2$ & 1619 & 28 & 26 & 30 & 30 & 31 & 23 & 1603 & 30 & 29 & 28 & 26 & 28 & 24 \\
\hline $3-4$ & 1268 & 32 & 28 & 26 & 19 & 17 & 14 & 1296 & 28 & 28 & 26 & 20 & 16 & 16 \\
\hline $5+$ & 1112 & 27 & 25 & 21 & 16 & 18 & 11 & 1343 & 26 & 26 & 23 & 22 & 22 & 19 \\
\hline \multicolumn{15}{|l|}{ Tea } \\
\hline 0 & 644 & 14 & 14 & 12 & 10 & 9 & 8 & 685 & 14 & 14 & 14 & 10 & 10 & 13 \\
\hline $1-2$ & 1240 & 32 & 29 & 24 & 18 & 16 & 10 & 1294 & 32 & 27 & 23 & 19 & 18 & 12 \\
\hline $3-4$ & 1756 & 33 & 29 & 33 & 32 & 30 & 29 & 1627 & 25 & 28 & 27 & 29 & 29 & 29 \\
\hline $5+$ & 2084 & 21 & 29 & 31 & 40 & 45 & 52 & 2237 & 29 & 31 & 36 & 42 & 43 & 47 \\
\hline
\end{tabular}

Sample sizes for coffee and tea include people with unspecified social class. ${ }^{\star}$ I: non-manual, professional; II: non-manual, intermediate; IIIn: non-manual, skilled; IIIm: manual, skilled; IV: manual, partially skilled; V: manual, unskilled. 
Table 5 Percentage drinking five or more cups of coffee, and of tea, per day by housing tenure, cigarette smoking, and activity status, by sex

\begin{tabular}{|c|c|c|c|c|c|c|}
\hline & \multicolumn{2}{|c|}{ Number } & \multicolumn{2}{|c|}{ Coffee } & \multicolumn{2}{|l|}{$\mathrm{Te} a$} \\
\hline & Men & Women & Men & Women & Men & Women \\
\hline \multicolumn{7}{|c|}{ Housing tenure status } \\
\hline Owner occupier & 3067 & 3009 & 23 & 25 & 31 & 33 \\
\hline Renter & 2668 & 2841 & 16 & 21 & 42 & 43 \\
\hline \multicolumn{7}{|c|}{ Cigarette smoking status } \\
\hline Never & 1468 & 2429 & 13 & 16 & 31 & 40 \\
\hline Ex & 1987 & 1180 & 19 & 25 & 37 & 32 \\
\hline Current & 2258 & 2227 & 25 & 30 & 40 & 40 \\
\hline \multicolumn{7}{|l|}{ Activity in work } \\
\hline Active & 2411 & 2774 & 18 & 23 & 39 & 39 \\
\hline Average & 2527 & 2812 & 19 & 23 & 35 & 38 \\
\hline Interactive & 754 & 264 & 26 & 23 & 31 & 38 \\
\hline \multicolumn{7}{|l|}{ Activity in leisure } \\
\hline Active & 1305 & 1124 & 19 & 25 & 34 & 34 \\
\hline Average & 3379 & 3633 & 20 & 22 & 36 & 40 \\
\hline Inactive & 1043 & 1095 & 21 & 27 & 40 & 38 \\
\hline
\end{tabular}

Sample sizes include some with missing data on coffee and/or tea consumption. Totals differ because of missing values for the row variables.

potential confounders; Spearman correlations (allowing for ties) were computed for each of the continuous confounders and KruskalWallis tests were used for the categorical confounders. Both coffee and tea consumptions were grouped into four groups, as near equal sized as possible. These were the groups used in our earlier paper $^{11}: 0,1-2,3-4$, and 5 and above cups per day for each drink. The Cox proportional hazards regression model was then used to produce hazard ratios relative to the zero consumption group for all three end points, for each sex. Survival time was recorded in days.

A range of checks were carried out to test the adequacy of the Cox model, particularly its assumption of proportional hazards. These included residual analyses and non-formal graphical procedures. ${ }^{21}$

The original surveys were approved by research ethics committees in each district studied. Only those participants who gave written consent to the study and to subsequent follow up of their morbidity and mortality are included in this investigation.

\section{Results}

The coffee consumption question was answered by 5645 men and 5800 women; tea consumption was answered by 5724 men and 5843 women. In each case this is at least a $98 \%$ completion rate. The number of cups of coffee drunk per day by the men ranged from 0 to 21 , and by the women ranged from 0 to 20 (quartiles $=0,2$, and 4 for each sex). The corresponding figures for tea were 0 to 30 for men and 0 to 36 for women (quartiles $=2,4$, and 6 for each sex).

Table 1 shows correlations for coffee and tea consumption and the 11 quantitative confounding variables considered in this study. The highest correlations are the negative ones between coffee and tea themselves: high consumers of tea tend to drink little coffee, and vice versa. Hence, correlations with the remaining variables have the opposite signs for

Table 6 Numbers (\%) of events and adjusted hazard ratios by outcome, sex, and coffee consumption group

\begin{tabular}{|c|c|c|c|c|c|c|c|c|}
\hline \multirow{3}{*}{$\begin{array}{l}\text { Coffee } \\
\text { consumption } \\
\text { (cups/day) }\end{array}$} & \multicolumn{4}{|l|}{ Men } & \multicolumn{4}{|l|}{ Women } \\
\hline & \multirow{2}{*}{$\begin{array}{l}\text { Number } \\
\text { (\%) of } \\
\text { events }\end{array}$} & \multicolumn{3}{|c|}{ Hazard ratios adjusted for } & \multirow{2}{*}{$\begin{array}{l}\text { Number } \\
(\%) \text { of } \\
\text { events }\end{array}$} & \multicolumn{3}{|c|}{ Hazard ratios adjusted for } \\
\hline & & Age & + Class* & Multiplet & & Age & + Class $^{*}$ & Multiplef \\
\hline \multicolumn{9}{|c|}{ Coronary death } \\
\hline 0 & $64(3.9)$ & 1 & 1 & 1 & $20(1.3)$ & 1 & 1 & 1 \\
\hline $1-2$ & $46(2.8)$ & 0.76 & 0.81 & 0.92 & $9(0.6)$ & 0.40 & 0.42 & 0.35 \\
\hline $3-4$ & $21(1.7)$ & 0.48 & 0.51 & 0.64 & $7(0.5)$ & 0.46 & 0.24 & 1.06 \\
\hline $5+$ & $25(2.2)$ & 0.72 & 0.78 & 0.59 & $9(0.7)$ & 0.69 & 0.79 & 1.05 \\
\hline Overall p & 0.002 & 0.02 & 0.19 & 0.50 & 0.06 & 0.09 & 0.05 & 0.54 \\
\hline Linear $\mathrm{p}$ & 0.001 & 0.02 & 0.06 & 0.15 & 0.06 & 0.23 & 0.25 & 0.93 \\
\hline \multicolumn{9}{|c|}{ Progressive CHD } \\
\hline 0 & $158(9.6)$ & 1 & 1 & 1 & $68(4.4)$ & 1 & 1 & 1 \\
\hline $1-2$ & $108(6.7)$ & 0.71 & 0.73 & 0.83 & $43(2.7)$ & 0.58 & 0.64 & 0.70 \\
\hline $3-4$ & $59(4.7)$ & 0.51 & 0.53 & 0.55 & $29(2.2)$ & 0.54 & 0.54 & 0.91 \\
\hline $5+$ & $72(6.5)$ & 0.76 & 0.78 & 0.58 & $30(2.2)$ & 0.58 & 0.69 & 1.18 \\
\hline Overall p & $<0.0001$ & $<0.0001$ & 0.002 & 0.04 & 0.001 & 0.006 & 0.06 & 0.53 \\
\hline Linear $\mathrm{p}$ & $<0.0001$ & 0.002 & 0.006 & 0.008 & 0.0005 & 0.005 & 0.03 & 0.75 \\
\hline \multicolumn{9}{|c|}{ All cause mortality } \\
\hline 0 & $139(8.4)$ & 1 & 1 & 1 & $72(4.6)$ & 1 & 1 & 1 \\
\hline $1-2$ & $101(6.2)$ & 0.77 & 0.83 & 0.74 & $63(3.9)$ & 0.81 & 0.85 & 0.92 \\
\hline $3-4$ & $67(5.3)$ & 0.69 & 0.78 & 0.74 & $30(2.3)$ & 0.53 & 0.51 & 0.77 \\
\hline $5+$ & $65(5.9)$ & 0.85 & 0.93 & 0.77 & $36(2.7)$ & 0.68 & 0.77 & 0.79 \\
\hline Overall p & 0.003 & 0.06 & 0.61 & 0.38 & 0.002 & 0.02 & 0.06 & 0.86 \\
\hline Linear p & 0.002 & 0.10 & 0.36 & 0.21 & 0.0005 & 0.008 & 0.05 & 0.43 \\
\hline
\end{tabular}

^Adjusted for age and occupational social class. †Adjusted for age, housing tenure, activity at work, activity in leisure, cigarette smoking status, body mass index, Bortner score, cotinine, systolic blood pressure, fibrinogen, total cholesterol, HDL-cholesterol, triglycerides, alcohol, vitamin C, and tea. $\mathrm{p}$ Values in the "number" column are from $\chi^{2}$ tests, ignoring censoring. All other $\mathrm{p}$ values are from Cox models. 
Table 7 Number (\%) of events and adjusted hazard ratios by outcome, sex, and tea consumption group

\begin{tabular}{|c|c|c|c|c|c|c|c|c|}
\hline \multirow{3}{*}{$\begin{array}{l}\text { Tea } \\
\text { consumption } \\
\text { (cups/day) }\end{array}$} & \multicolumn{4}{|l|}{ Men } & \multicolumn{4}{|l|}{ Women } \\
\hline & \multirow{2}{*}{$\begin{array}{l}\text { Number } \\
(\%) \text { of } \\
\text { events }\end{array}$} & \multicolumn{3}{|c|}{ Hazard ratios adjusted for } & \multirow{2}{*}{$\begin{array}{l}\text { Number } \\
(\%) \text { of } \\
\text { events }\end{array}$} & \multicolumn{3}{|c|}{ Hazard ratios adjusted for } \\
\hline & & Age & + Class $^{*}$ & Multiplet & & Age & + Class $^{*}$ & Multiplet \\
\hline \multicolumn{9}{|c|}{ Coronary death } \\
\hline 0 & $12(1.9)$ & 1 & 1 & 1 & $5(0.7)$ & 1 & 1 & 1 \\
\hline $1-2$ & $27(2.2)$ & 1.01 & 1.02 & 2.53 & $10(0.8)$ & 0.88 & 0.53 & 2.71 \\
\hline $3-4$ & $44(2.5)$ & 1.08 & 1.03 & 2.22 & $9(0.6)$ & 0.54 & 0.45 & 1.91 \\
\hline $5+$ & $76(3.7)$ & 1.44 & 1.35 & 2.19 & $23(1.0)$ & 0.93 & 0.79 & 2.77 \\
\hline Overall p & 0.02 & 0.24 & 0.72 & 0.49 & 0.43 & 0.51 & 0.54 & 0.82 \\
\hline Linear $\mathrm{p}$ & 0.003 & 0.06 & 0.15 & 0.64 & 0.36 & 0.97 & 0.79 & 0.62 \\
\hline \multicolumn{9}{|c|}{ Progressive CHD } \\
\hline 0 & $37(5.8)$ & 1 & 1 & 1 & $13(1.9)$ & 1 & 1 & 1 \\
\hline $1-2$ & $76(6.1)$ & 0.97 & 1.01 & 1.54 & $30(2.3)$ & 1.13 & 1.01 & 1.28 \\
\hline $3-4$ & $117(6.7)$ & 1.01 & 1.02 & 0.98 & $47(2.9)$ & 1.30 & 1.10 & 1.34 \\
\hline $5+$ & $172(8.2)$ & 1.19 & 1.16 & 1.03 & $86(3.8)$ & 1.63 & 1.43 & 1.82 \\
\hline Overall p & 0.04 & 0.36 & 0.88 & 0.11 & 0.02 & 0.16 & 0.42 & 0.54 \\
\hline Linear $\mathrm{p}$ & 0.007 & 0.13 & 0.25 & 0.37 & 0.001 & 0.02 & 0.07 & 0.16 \\
\hline \multicolumn{9}{|c|}{ All cause mortality } \\
\hline 0 & $40(6.2)$ & 1 & 1 & 1 & $19(2.8)$ & 1 & 1 & 1 \\
\hline $1-2$ & $63(5.1)$ & 0.71 & 0.77 & 1.06 & $32(2.5)$ & 0.81 & 0.66 & 1.73 \\
\hline $3-4$ & $114(6.5)$ & 0.84 & 0.85 & 1.16 & $58(3.6)$ & 1.07 & 0.93 & 1.89 \\
\hline $5+$ & $164(7.9)$ & 0.94 & 0.92 & 1.01 & $98(4.4)$ & 1.24 & 1.12 & 2.06 \\
\hline Overall p & 0.02 & 0.18 & 0.81 & 0.88 & 0.02 & 0.19 & 0.20 & 0.58 \\
\hline Linear $p$ & 0.008 & 0.37 & 0.72 & 0.92 & 0.003 & 0.07 & 0.10 & 0.25 \\
\hline
\end{tabular}

*Adjusted for age and occupational social class. †Adjusted for age, housing tenure, activity at work, activity in leisure, cigarette smoking status, body mass index, Bortner score, cotinine, systolic blood pressure, fibrinogen, total cholesterol, HDL-cholesterol, triglycerides, alcohol, vitamin C, and coffee. $p$ Values in the "number" column are from $\chi^{2}$ tests, ignoring censoring. All other $p$ values are from Cox models.

coffee and tea, except sometimes where they are near zero. The highest correlations in this set are for age, alcohol (except for male coffee drinkers) and Bortner score. Systolic blood
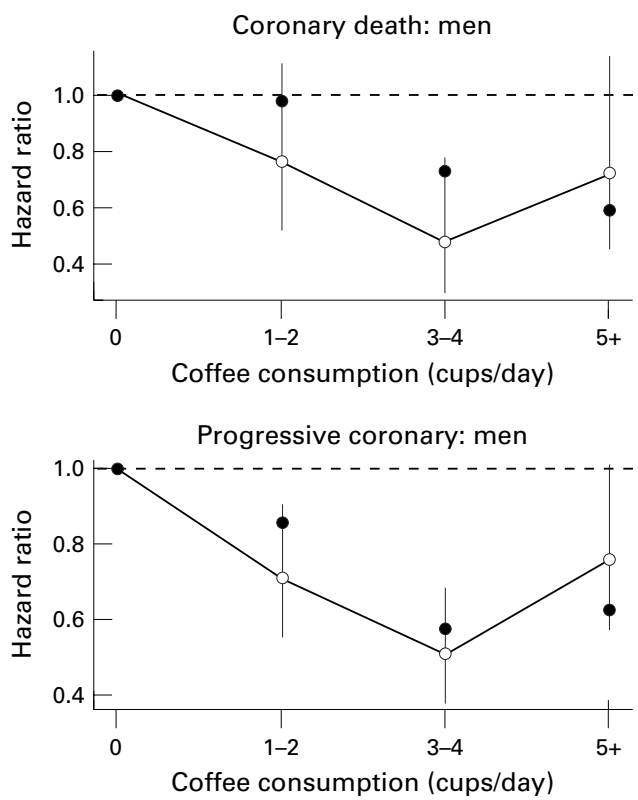

All cause mortality: men

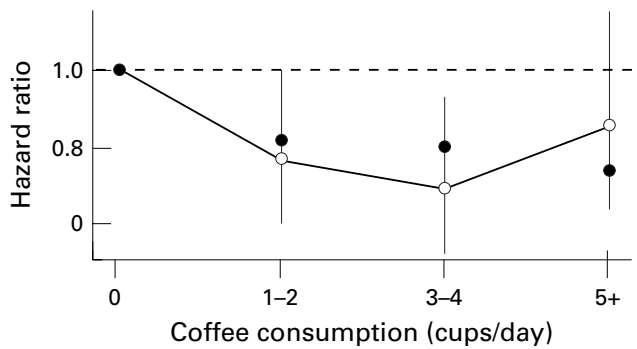

pressure is negatively correlated with coffee drinking for both sexes, and positively, but less strongly, related with tea. Because of the large sample size, modest correlations are associated
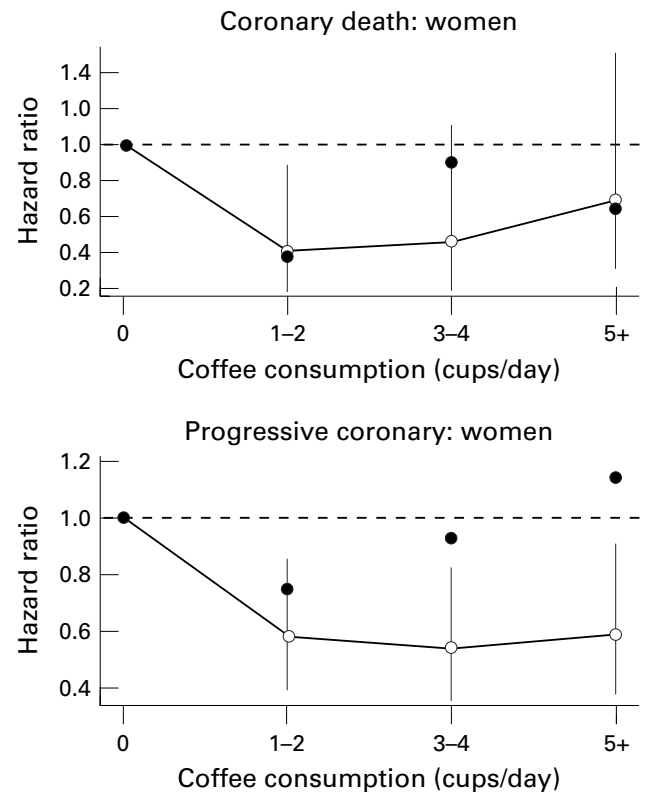

All cause mortality: women

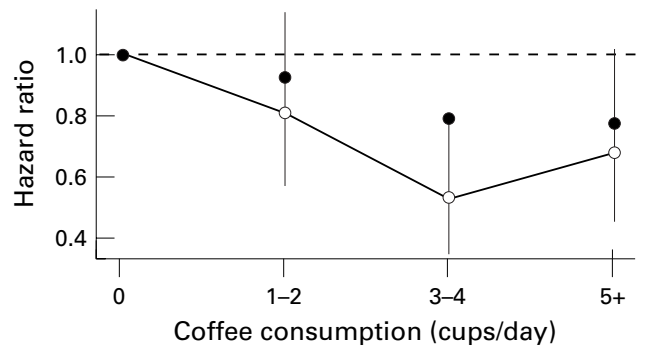

Figure 1 Hazard ratios by coffee consumption group (base = zero consumption). Age adjusted hazard ratios are marked with open circles, are joined and are shown with 95\% confidence limits. The closed circles show hazard ratios after adjustment for age, housing tenure, activity in work, activity in leisure, cigarette smoking status, Bortner score, alcohol consumption, vitamin $C$ intake, body mass index, cotinine and tea consumption. 


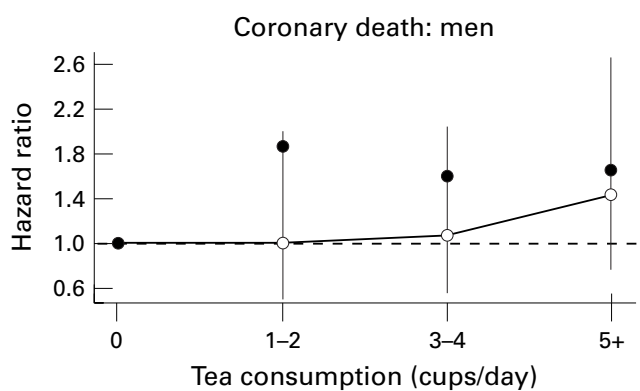

Progressive coronary: men

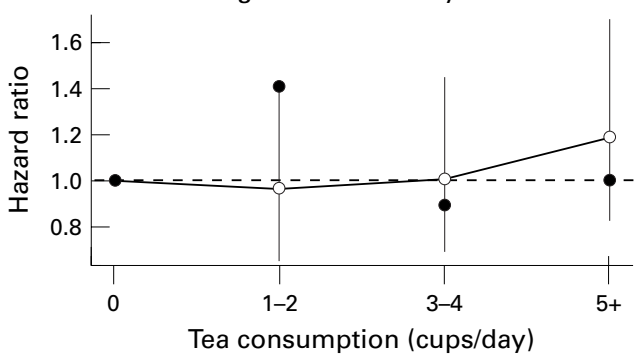

All cause mortality: men

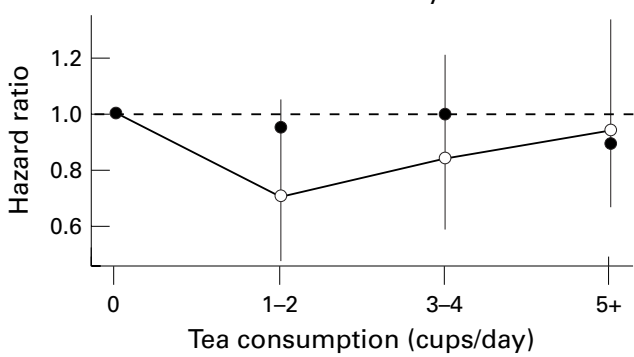

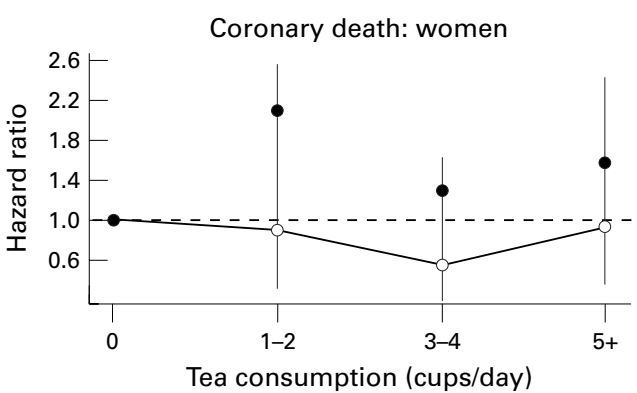

Progressive coronary: women

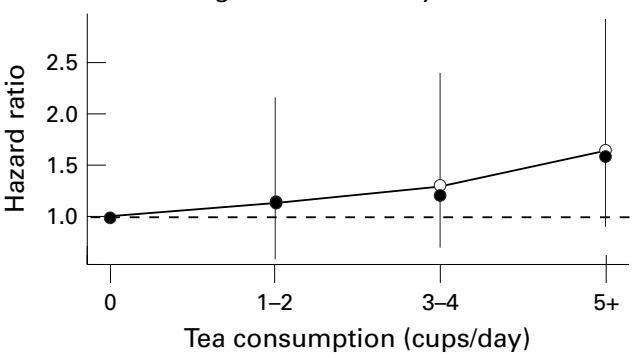

All cause mortality: women

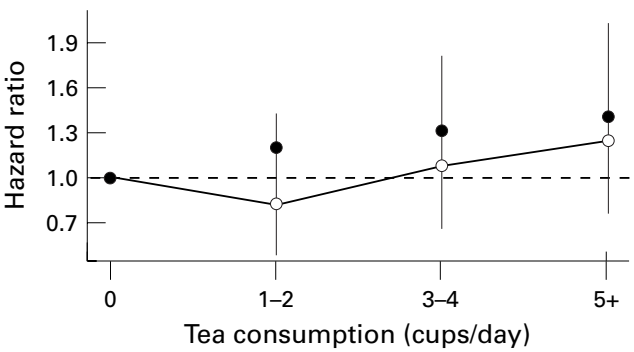

Figure 2 Hazard ratios by tea consumption group (base = zero consumption). Age adjusted hazard ratios are marked with open circles, are joined and are shown with 95\% confidence limits. The closed circles show hazard ratios after adjustment for age, housing tenure, activity in work, activity in leisure, cigarette smoking status, Bortner score, alcohol consumption, vitamin $C$ intake, body mass index, cotinine and coffee consumption.

with extreme significance levels. Tables 2 and 3 show median levels for each of the quantitative confounding variables according to coffee or tea group.

The percentage drinking no coffee decreases as social status increases across the six point occupational scale for men and women (table 4). On average, people in rented accommodation drink one cup of coffee less and one cup of tea more per day than those who own their own houses $(p<0.0001$ for both drinks and for both sexes). Table 5 shows the percentage drinking five or more cups of coffee, and of tea, by housing tenure status. Coffee and tea consumption also varies with cigarette smoking status $(p \leqslant 0.0002$ in each case). Current smokers, of either sex, consume more of both drinks than either never or ex smokers: of current smokers, $25 \%$ of men and $30 \%$ of women drink five or more cups per day; the corresponding percentages for tea are both $40 \%$ (table 5). Never smokers drink less coffee than current or ex smokers: of never smokers, $13 \%$ of men and $16 \%$ of women drink five or more cups of coffee per day (table 5). Men who are inactive at work drink most coffee and least tea $(p<0.0001$ for both drinks), but activity at work has no significant relation with coffee or tea drinking for women $(p \geqslant 0.28)$. Men who are inactive during leisure time drink most tea $(p=0.02)$, although leisure activity has no significant relation with their coffee consumption $(p=0.15)$. Those women who are active in their leisure time drink slightly more coffee $(p=0.02)$ and less tea $(p=0.0002)$. Table 5 includes summary measures of relatively heavy coffee and tea drinking by activity status.

Tables 6 and 7 include comparisons of the number of coronary events and deaths by coffee and tea groups. For all three types of event, and for both sex groups, the chance of an event decreases as coffee consumption increases, and increases as tea consumption increases. Except in the case of female coronary deaths (where there are only 47 events) the trend is extremely significant $(p \leqslant 0.008)$. The same two tables show hazard ratios (relative to the zero consumption group) after age adjustment, adjustment for age and occupational social class and adjustment for all the potential confounding variables (except occupational social class, which is superfluous when housing tenure is included) identified earlier, including the other beverage.

Age adjusted hazard ratios for coffee show a downward trend combined with a $U$ shaped response; however, the confidence intervals are wide (fig 1). The linear trend in the log hazards is significant $(p<0.05)$, or nearly so, except for all cause mortality in men. Tests for non-linearity 
were also carried out: $p$ values of below 0.1 were found only for progressive CHD in men $(p=0.002)$ and coronary death in women $(\mathrm{p}=0.08)$. Extra adjustment for occupational social class tends to move the hazard ratios towards unity and increase the $\mathrm{p}$ values, but leaves the patterns in the hazard ratios much the same. The same two significant non-linear effects as before were found. Multiple adjusted hazard ratios for coffee in men show similar patterns to those for age adjustment, although only progressive CHD now has significant differences. All hazard ratios for male coffee drinkers are below one (indicating decreased risk). In women, the $U$ shaped patterns for progressive $\mathrm{CHD}$ and all cause mortality remain after multiple adjustment, but there are no significant effects. There are no significant non-linear effects of coffee consumption after multiple adjustment.

Age adjusted hazard ratios for tea generally show a flat response or an upward trend; all the $95 \%$ confidence intervals include unity (fig 2 ). There is a substantial linear trend in the log hazards for coronary death in men, progressive CHD in women and all cause mortality in women. Adjustment for occupational social class removes the trend, except for female progressive CHD. Multiple adjusted hazard ratios for tea drinkers are above one (indicating increased risk) in all but the 3-4 cups per day group for progressive CHD in men. All hazard ratios are above two for coronary death in men and are increasing for progressive CHD and all cause mortality in women. However, the confidence limits (not shown) are wide, and there are consequently no significant effects. For tea, tests for non-linearity are not significant after all three types of adjustment used in table 7 .

Figures 1 and 2 show the hazard ratios adjusted for age and for all the "non-mediated" confounding variables, that is omitting lipids, fibrinogen and systolic blood pressure, which might themselves be mediated by coffee or tea. Compared with age adjustment, hazard ratios for non-zero consumptions relative to zero consumption are higher for progressive coronary disease among female coffee drinkers and for coronary death among tea drinkers. The "non-mediated" adjustments are very similar to the multiple adjustments for coffee drinking. For tea drinking, they have less extreme effects, but in the same direction as the multiple adjustments.

To be sure that the effects seen for CHD were not simply attributable to the influence of pre-existing disease, we re-ran our models for coronary events excluding those people with CHD (angina or myocardial infarction) at baseline. The hazard ratios for multiple adjustment (as in tables 6 and 7) turned out to be quite similar to those for progressive CHD. Using the same increasing consumption groups as in the tables, the hazard ratios $(95 \%$ confidence intervals) for coffee were $1,0.68$ $(0.42,1.10), 0.39(0.21,0.73), 0.68(0.37$, $1.24)$ for men and $1,0.54(0.22,1.34), 0.56$ $(0.20,1.56), 0.55(0.18,1.66)$ for women. The corresponding hazard ratios for tea were 1 , 1.83 (0.92, 3.63), 1.09 (0.52, 2.28), 1.10
KEY POINTS

- In Scotland coffee drinking is associated with good health.

- In Scotland tea drinking is unrelated to health.

- More tea is drunk by the more socially disadvantaged; the opposite is true for coffee.

- These findings may not be replicated elsewhere where the types of coffee and tea consumed are different.

$(0.51,2.37)$ for men and $1,1.32(0.36,4.80)$, $1.10(0.28,4.31), 1.06(0.28,4.05)$ for women, showing no dose response effect.

\section{Discussion}

Our unadjusted results suggest that those who drink more coffee and less tea have less chance of either a coronary event or death. This might be attributable to "real" effects of coffee and tea, to chance or to confounding. Coffee and tea drinking habits might simply be identifying (at the extreme) two groups of people with very different lifestyles. For instance, coffee drinking may be one element of a youthful, modern lifestyle with general benefits to health. Tea is the traditional mass consumption British beverage, established over a century or more, whereas coffee is more expensive and is associated in the public mind, and in our analyses, with a cosmopolitan lifestyle.

The correlations in table 1 suggest an inverse association between coffee and tea consumption, and show that coffee drinkers are younger. The association with age seems to explain some of the coffee and tea effects, but there are still residual effects, particularly a benefit of moderate coffee consumption. The percentages in table 4 suggest associations with increasing deprivation: positive for tea consumption and negative for coffee consumption. However, further adjustment for occupational social class did not change patterns of response in a major fashion. Adjustment for a large number of potential confounding variables produces hazard ratios that show the same type of effects as the age adjusted hazard ratios for men, but are less similar for women. The smaller number of events for women might be a contributory factor. The relative lack of significance after multiple adjustment is partially attributable to there being several missing values for some confounders, thus reducing the effective sample size. Our study is insufficiently powerful to allow definitive tests for interactions with coffee and tea drinking, but where we have tested for them (for example, in the case of smoking status and social class) they have not been significant $(p>0.1)$, in tests arising from Cox models.

Our analyses have shown some tendency for a beneficial association of coffee consumption with coronary risk factors, coronary risk and mortality, and the converse for tea, although adjusted results are rarely statistically significant. As in other observational studies, we are unable to definitively exclude the possibility of 
residual confounding factors. Furthermore, we cannot rule out selection bias: people may have switched from coffee to tea after first becoming unwell, before our study began.

Our findings, although showing agreement (for tea) with results from Caerphilly ${ }^{22}$ are at variance with some of the scientific literature (including a recent study of coffee in west Scotland ${ }^{23}$ ). Although both beverages contain caffeine, coffee is seen as the more potent source and its association, in large doses, with palpitation (although its linkage with cardiac extrasystoles is dubious ${ }^{24}$ ) has inexorably linked it to heart disease in popular medicine. It has also suffered adverse publicity from the association between the boiling of coffee in Scandinavia, high heart disease rates, and the lipid raising effects of certain associated constituents. $^{25} 26$ Tea, on the other hand, contains polyphenol flavonoids, which are thought to be beneficial in acting as antioxidants. ${ }^{67}$ For both beverages, the constituents present, their concentration in the local brew, and whether or how rapidly they are absorbed will depend on the varieties of plant used, their processing, the method of infusion and whether milk, cream or other supplements are added before consumption. The typical cup of coffee drunk in the UK may be much less harmful than that drunk elsewhere, while the tea drunk may not be as beneficial to health as that drunk in some other countries.

Our analyses suggest a general picture, in Scotland, of moderate risk benefit from coffee consumption and very little effect, but if anything tending to be in the harmful direction, for tea consumption. This is the opposite of popular expectation. The most likely explanation for our findings is that we have not been able to remove all confounding effects, particularly those associated with relative deprivation.

The views expressed here are those of the authors. Thanks to Susan Talbot, a student on the MSc in Biometry at Reading in 1997, whose thesis includes preliminary results and details of model checking. We wish to remember Dr Colin Brown, whose untimely death followed shortly after leading previous cross sectional analyses of the data.

Funding: this study was funded by the Chief Scientist Office of the Scottish Office Department of Health and the British Heart Foundation.

Conflicts of interest: none.

1 Dews PB. Caffeine. Prospectives from recent research. New York: Springer-Verlag, 1984.
2 Christensen L, Murray BS. A review of the relationship between coffee consumption and coronary heart disease. $\mathcal{F}$ between coffee consumption and coro

3 Myers MG, Basinski A. Coffee and coronary heart disease. Arch Intern Med 1992;152:1767-72.

4 Greenland S. A meta-analysis of coffee, myocardial infarction, and coronary death. Epidemiology 1993;4:36674.

5 Kawachi I, Colditz GA, Stone CB. Does coffee drinking increase the risk of coronary heart disease? Results from a meta-analysis. Br Heart 7 1994;72:269-75.

6 Robinson EE, Maxwell SRJ, Thorpe GHG. An investigation of the antioxidant activity of black tea using enhanced of the antioxidant activity of black tea using enhan
chemiluminescence. Free Radic Res 1997;26:291-302.

7 Landau JM, Yang CS. The effect of tea on health. Chemistry Landau JM, Yang CS. The effect

8 Baron JA, De Verdier MG, Ekbom A. Coffee, tea, tobacco and cancer of the large bowel. Cancer Epidemiol Biomarkers Prev 1996;3:565-70.

9 Nishi M, Ohba S, Hirata $\mathrm{K}$, et al. Dose-response relationship between coffee and the risk of pancreas cancer. fpn F Clin Oncol 1996;26:42-8.

10 Blot WJ, Chow WH, McLaughlin JK. Tea and cancer: a review of the epidemiological evidence. Eur $\mathcal{F}$ Cancer Prev 1996:5:425-38.

11 Brown CA, Bolton-Smith C, Woodward M, et al. Coffee and tea consumption and the prevalence of coronary heart disease in men and women: results from the Scottish Heart Health Study. F Epidemiol Community Health 1993;47:1715.

12 Klag MJ, Mead LA, La Croix A, et al. Coffee intake and coronary heart disease. Ann Epidemiol 1994;4:425-33.

13 Willett WC, Stampfer MJ, Manson JE, et al. Coffee consumption and coronary heart disease in women. A tenyear follow-up. $\mathcal{F} A M A ; 275: 458-62$.

14 Prineas RJ, Crow RS, Blackburn H. The Minnesota code manual of electrographic findings. Bristol: John Wright, 1982.

15 Smith WCS, Crombie IK, Tavendale R, et al. The Scottish Heart Health Study: objectives and development of methods. Health Bull (Edinb) 1987;45:211-17.

16 Smith WCS, Tunstall-Pedoe H, Crombie IK, et al. Concomitants of excess coronary deaths: Major risk factor and lifestyle findings from 10,359 men and women in the Scottish Heart Health Study. Scott Med f 1989;34:550-5.

17 Tunstall-Pedoe $\mathrm{H}$, Woodward $\mathrm{M}$, Tavendale $\mathrm{R}$, et al. Comparison of the prediction by 27 different factors of coronary heart disease and death in men and women of the Scottish heart health study: cohort study. BMF 1997;315: $722-9$.

18 Woodward M, Lowe GDO, Rumley A, et al. Fibrinogen as a risk factor for coronary heart disease and mortality in middle-aged men and women. The Scottish Heart Health Study. Eur Heart 7 1998;19:1257-60.

19 Woodward M, Shewry MC, Smith WCS, et al. Social status and coronary heart disease: results from the Scottish Heart Health Study. Prev Med 1992;21:136-48.

20 Bolton-Smith C, Woodward M, Tunstall-Pedoe H. The Scottish Heart Health Study. Dietary intake by food frequency questionnaire and odds ratios for coronary heart disease risk. II. The antioxidant vitamins and fibre. Eur $\mathcal{f}$ Clin Nutr 1992;46:85-93

21 Collett D. Modelling survival data in medical research. London: Chapman and Hall, 1994.

22 Hertog MC, Sweetnam PM, Fehily AM, et al. Antioxidant flavonols and ischaemic heart disease in a Welsh population of men: the Caerphilly Study. Am f Clin Nutr 1997;65: 1489-94.

23 Hart C, Davey Smith G. Coffee consumption and coronary heart disease mortality in Scottish men: a 21 year follow up study. F Epidemiol Community Health 1997;51:461-2.

24 Myers MG. Caffeine and cardiac arryhthmias. Am Intern Med 1991:114:147-50.

25 Thelle DS, Heyden S, Fodor JG. Coffee and cholesterol in epidemiological and experimental studies. Atherosclerosis 1987;67:97-103.

26 Urgent R, Katan MB. The cholesterol-raising factor from coffee beans. Anпu Rev Nutr 1997;17:305-24. 